\title{
Determining Effective Riparian Buffer Width for Nonnative Plant Exclusion and Habitat Enhancement
}

\author{
Gavin Ferris, ${ }^{1}$ Vincent D'Amico, ${ }^{2}$ and Christopher K. Williams ${ }^{1}$ \\ ${ }^{1}$ Department of Entomology \& Wildlife Ecology, University of Delaware, Newark, DE 19716, USA \\ ${ }^{2}$ US Forest Service, Newark, DE 19716, USA \\ Correspondence should be addressed to Christopher K. Williams, ckwillia@udel.edu
}

Received 16 August 2011; Revised 8 January 2012; Accepted 9 January 2012

Academic Editor: Patricia Mosto

Copyright () 2012 Gavin Ferris et al. This is an open access article distributed under the Creative Commons Attribution License, which permits unrestricted use, distribution, and reproduction in any medium, provided the original work is properly cited.

\begin{abstract}
Nonnative plants threaten native biodiversity in landscapes where habitats are fragmented. Unfortunately, in developed areas, much of the remaining forested habitat occurs in fragmented riparian corridors. Because forested corridors of sufficient width may allow forest interior specializing native species to retain competitive advantage over edge specialist and generalist nonnative plants, identifying appropriate corridor widths to minimize nonnative plants and maximize ecosystem integrity is of habitat management concern. We measured the occurrences of 4 species of nonnative plants across the widths of 31 forested riparian corridors of varying widths in the White Clay Creek watershed of Pennsylvania and Delaware. Using repeated measures ANOVA, Japanese honeysuckle (Lonicera japonica) and multiflora rose (Rosa multiflora) prevalence did not significantly decline across buffer widths. However, garlic mustard (Alliaria petiolata) and oriental bittersweet (Celastrus orbiculatus) declined strongly within the first 15$25 \mathrm{~m}$. Managing for riparian corridor widths a minimum of $15-25 \mathrm{~m}$ has the potential to enhance habitat quality but no corridor width $(\leq 55 \mathrm{~m})$ will exclude all invasive plants.
\end{abstract}

\section{Introduction}

Fragmentation of formerly intact habitats is an unavoidable consequence of human utilization and has resulted in patchy natural habitats in most human-dominated landscapes, especially in the eastern United States [1]. For many species, fragmentation contributes to habitat and resource loss, reduced gene flow, edge effects, and increased time in an inhospitable matrix leading to higher mortality and decreased reproductive rates [2]. Forested riparian buffers may serve as de facto corridors in some of these fragmented landscapes, but in other cases they may be the only appreciable forested habitat remaining. If preserving native biodiversity in human-dominated landscapes is to be a priority, then these forested riparian areas provide a critical opportunity for conservation.

One way of improving the habitat value of forested riparian corridors, and thus protecting biodiversity in the fragmented habitats in which they exist, is to protect the integrity of the food web supported within them. A common reduction in this integrity occurs when nonnative plants dominate the foundation of a trophic pyramid. Herbaceous plants native to temperate forests are vulnerable to edge effects as a consequence of their low dispersal, slow growth rates, long prereproductive periods, and low reproductive outputs [3-5]. Alternatively, most nonnative plant species are generalists or edge-specialists, which often make them the dominant competitor in fragmented habitats [6]. Increased nutrient loads due to agricultural and residential runoff $[7,8]$ may further increase the competitiveness of nonnative plants, thus further endangering native plant biodiversity [9].

As the foundation of the trophic pyramid is altered by nonnative plants, the enemy release hypothesis postulates that native herbivores will be less likely to feed on these plants whose defenses they have not evolved to overcome $[10,11]$. A logical extension of this concept suggests that a potential consequence of nonnative plant dominance is a decrease in native herbivore (especially arthropod) diversity and biomass that exist in these altered trophic pyramids [12-17]. Therefore, invasion by nonnative plants may trigger a trophic cascade [18] negatively affecting higher trophic levels.

It is typical that riparian buffer width recommendations

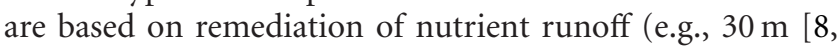
19]). Unfortunately, existing guidelines for riparian buffers 
widths intended to provide wildlife habitat or ecosystem health are generally based on expert opinion rather than empirical data, and nonnative plants are hardly mentioned except to say that intentional plantings should be of native species $[8,20]$. The shade and lower rates of disturbance offered by forest interiors make them less prone to invasion by many nonnative plants than edge habitats $[21,22]$. If managers can determine a distance from buffer edge at which nonnative plant prevalence is significantly reduced, then management guidelines can be established for making these mitigation efforts more valuable for conservation by preserving trophic integrity. It is the goal of this research to identify prevalence patterns of 4 common nonnative plants across different widths of riparian buffers to improve habitat management guidelines.

\section{Study Area}

Our research was focused within the White Clay Creek watershed of Chester County, Pennsylvania, and New Castle County, Delaware. The White Clay Creek watershed is part of the Piedmont Physiographic Region and drains into the Delaware Bay. The major land uses within the 27,923 ha watershed are agriculture (36\%), wooded/open space (29\%), and residential (25\%) [23]. Some 60 tree and shrub species are found within the watershed, as well as more than 200 wildflowers. White Clay Creek itself has been declared a National Wild and Scenic River.

During the summers of 2007-2008, we used Geographic Information Systems to establish 1500 randomly placed points along first- and second-order streams in the White Clay Creek watershed. We further ground truthed these points to select study sites that met all of the following criteria in an effort to reduce bias: (1) relatively equal forested buffer width on both sides of the stream, (2) similar land use (agricultural versus residential) on both sides of the stream, (3) was not recently disturbed by human activity, and (4) had a forest structure and width similar to that of the rest of the corridor within $100 \mathrm{~m}$ up and downstream from the point. Thirty-one sites met these 4 criteria (Figure 1).

\section{Methods}

At each site, we established 3 line transects that were $5 \mathrm{~m}$ apart and were perpendicular to the buffer. Transects ran from the edge of the forested section of the corridor to the stream bank with the outside edge of the corridor being defined as even with the upland side of trunks of the outermost canopy trees $(>10 \mathrm{~m})$. Each measured corridor was considered the sampling unit, and we measured the response of distance from edge on nonnative prevalence within that sampling unit. The distance between the stream and the corridor edge measured $10 \mathrm{~m}$ in 7 sites, $20 \mathrm{~m}$ in 4 sites, $35 \mathrm{~m}$ in 8 sites, $55 \mathrm{~m}$ in 7 sites, and $80 \mathrm{~m}$ in 5 sites.

We recorded the occurrence of 4 common nonnative plants using a slightly modified version of the transect method described by Canfield [24]. The line interception method is based on a foundation that the sampling unit is a line transect, which is visualized having length and vertical dimensions only with no width, and the researcher only measures the intercept of plants through the vertical plane. Along each transect, we laid a metric measuring tape and recorded the percent interception of oriental bittersweet (Celastrus orbiculatus), Japanese honeysuckle (Lonicera japonica), multiflora rose (Rosa multiflora), and garlic mustard (Alliaria petiolata) occurring underneath the tape within each $5 \mathrm{~m}$ of the length of the transect. We averaged the 3 transects to calculate site level percentages across the buffer. At both ends of each transect and at $5 \mathrm{~m}$ increments beginning at the outside edge, we estimated canopy coverage using a densitometer and recorded an index of basal area using a forester's $10 \mathrm{X}$ cruising prism. We used repeated measures ANOVA $(\alpha=0.10$ (to account for a lower sample size of measured streams that met our sampling criteria), with GreenhouseGeisser corrections to account for violations of sphericity) to determine if each nonnative species prevalence changed with increasing distance from forested riparian edge while considering between corridor effects and within-corridor covariates of canopy coverage, basal density, and total buffer width. We made the assumption (based on visual assessments) that vegetation composition and structure were spatially autocorrelated at increasing distances from corridor edges and therefore repeated measures ANOVA was a necessary statistic (as compared to the use of linear regression when data points are assumed independent of each other). Although repeated measures is often used for measuring autocorrelated temporal changes, its fundamental statistical structure allows for analysis of vegetation changes spatially changing at further distances from the edge. Repeated-measures analysis further analyzes the statistical probability $(\alpha=0.10)$ that within subject effects (nonnative prevalence away from corridor edge) are explained by linear, quadratic, or cubic relationships. If a significant relationship existed in any or all three trends, we only reported the one trend shape with the strongest statistical support. Because the forested riparian corridors measured were of different widths, we could not run a single repeated measures ANOVA on the whole data set (testing for trends over $80 \mathrm{~m}$ ) because a repeated measures ANOVA is sensitive to missing data. Rather we conducted a series of step wise repeated measurements including all corridors that had data within set distance bands. For example, all 31 corridors could be used to determine if nonnative prevalence changed at $5 \mathrm{~m}$ increments within the first $10 \mathrm{~m}$. However, only 24 sites could be used to test if nonnative prevalence changed at $5 \mathrm{~m}$ increments within the first $20 \mathrm{~m}$. Additionally, only 20 sites could test for differences across $35 \mathrm{~m}, 12$ sites could test for differences across $55 \mathrm{~m}$, and 5 sites could test for differences across $80 \mathrm{~m}$.

\section{Results}

Although the prevalence of Japanese honeysuckle appeared to show a decline away from riparian buffer edges, high variances produced no main effects on distance, buffer width, canopy coverage, or basal density (Table 1, Figure 2). The prevalence of garlic mustard at $10 \mathrm{~m}$ was affected by the positive main effects of distance and distance/canopy coverage 


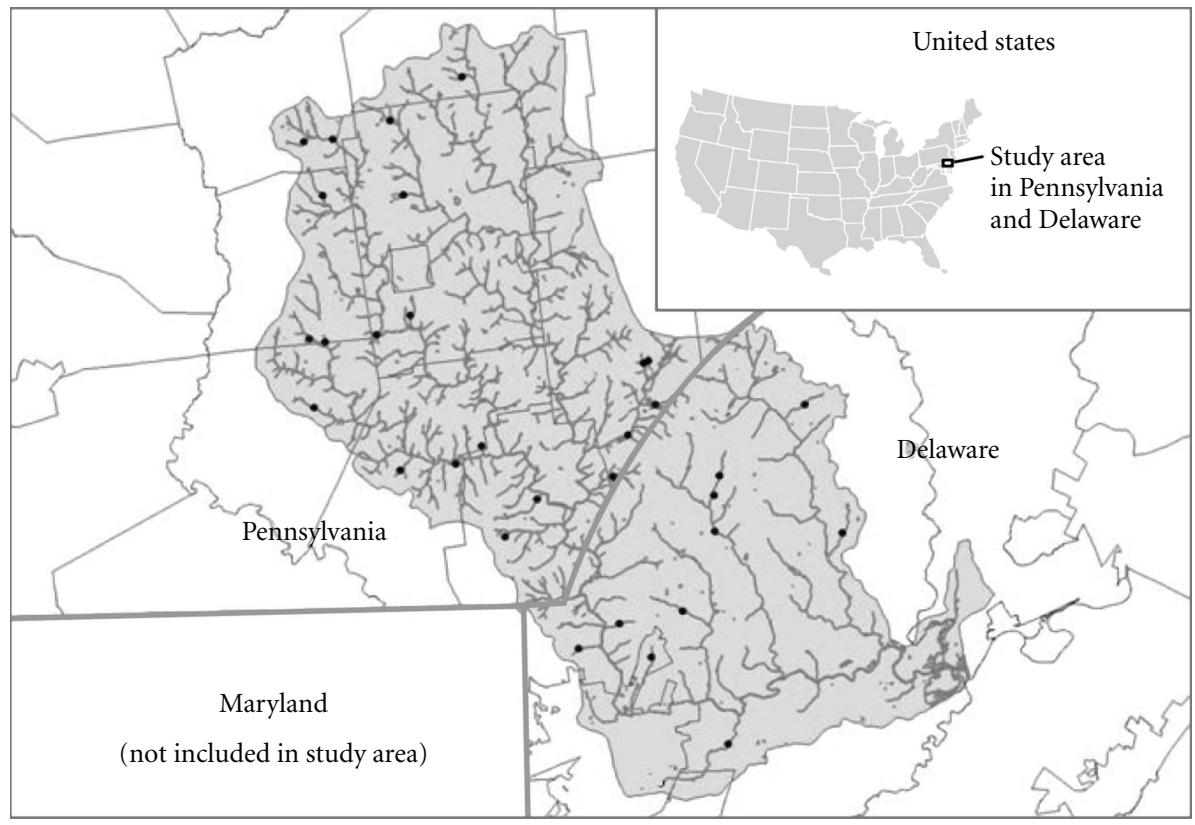

Figure 1: Thirty-one study sites within White Clay Creek watershed of Chester County, Pennsylvania, and New Castle County, Delaware, USA.



FIgURE 2: The prevalence of Japanese honeysuckle away from the edge of forested riparian buffers in Delaware and Pennsylvania, 2007-2008.

interaction $\left(F_{1,17}=4.96, P=0.04\right.$ and $F_{1,17}=5.30$, $P=0.03$, respectively, Table 1$)$ following a linear trend $\left(F_{1,17}=4.96, P=0.04\right.$, Figure 3$)$. At $20 \mathrm{~m}$, distance $/$ total buffer width interaction showed significant reductions in garlic mustard $\left(F_{18.57,20.43}=1.81, P=0.10\right.$, Table 1$)$ but the within-subject contrast failed to detect any slope structure (Figure 3). Beyond $25 \mathrm{~m}$, the mean prevalence of garlic mustard remained at low levels (1-7\%).

The prevalence of multiflora rose showed no reduction at $10 \mathrm{~m}$ as a function of the main effects of distance, total buffer width, basal density, or canopy coverage. However, at $20 \mathrm{~m}$ distance, distance/total buffer width interaction, and distance/canopy coverage interaction showed significant

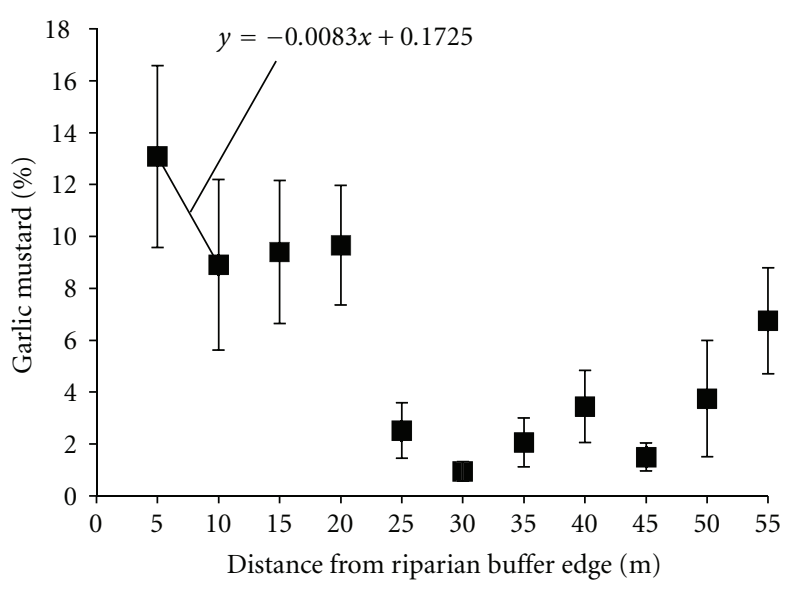

Figure 3: The prevalence of garlic mustard away from the edge of forested riparian buffers in Delaware and Pennsylvania, 2007-2008. Within-subject contrasts indicated a significant $(P<0.10)$ linear trend through $10 \mathrm{~m}$.

main effects on the reduction of multiflora rose $\left(F_{1.98,19.84}=\right.$ 2.88, $P=0.08 ; F_{1.98,19.84}=2.70, P=0.09$; and $F_{21.83,19.84}=$ $1.88, P=0.08$, respectively, Table 1$)$ following a quadratic trend $\left(F_{1,10}=10.86, P<0.01\right.$, Figure 4$)$. No within-subject main effects were observed at $35 \mathrm{~m}$; however, significant between-sample effects occurred $\left(F_{1,9}=4.38, P=0.07\right.$, Table 1). At $55 \mathrm{~m}$, distance and distance/canopy coverage interaction showed significant positive main effects on the reduction of multiflora rose $\left(F_{2.70,10.81}=2.99, P=0.08\right.$ and $F_{2.70,10.81}=3.00, P=0.08$, respectively, Table 1) following an increasing linear trend $\left(F_{1,4}=4.49, P=0.10\right.$, Figure 4$)$. 
TABLE 1: Summary of repeated measures ANOVA models on nonnative prevalence across multiple riparian buffer widths in Delaware and Pennsylvania, 2007-2008. We tested for within-sample effect of distance from buffer edge as well as the interaction between distance and total riparian buffer width, basal density at sampled distance, and canopy coverage at sampled distance. Stars indicate significance $(P \leq 0.10)$. We further tested for trends across buffer width exhibiting significant $(P \leq 0.10)$ linear, quadratic, or cubic relationships.

\begin{tabular}{|c|c|c|c|c|c|}
\hline \multirow{3}{*}{ Species } & \multirow{3}{*}{ Repeated measures ANOVA model } & \multicolumn{4}{|c|}{ Distance $(\mathrm{m})$} \\
\hline & & 10 & 20 & 35 & 55 \\
\hline & & $n=31$ & $n=24$ & $n=20$ & $n=12$ \\
\hline \multirow{5}{*}{ Japanese honeysuckle } & Distance & - & - & - & - \\
\hline & Distance contrast & - & - & - & - \\
\hline & Distance $*$ total buffer width & - & - & - & - \\
\hline & Distance $*$ basal density & - & - & - & - \\
\hline & Distance $*$ canopy coverage & - & - & - & - \\
\hline \multirow{7}{*}{ Garlic mustard } & Between sample effect & - & - & - & - \\
\hline & Distance & $*$ & - & - & - \\
\hline & Distance contrast & Linear & - & - & - \\
\hline & Distance $*$ total buffer width & - & $*$ & - & - \\
\hline & Distance $*$ basal density & - & - & - & - \\
\hline & Distance $*$ canopy coverage & $*$ & - & - & - \\
\hline & Between sample effect & - & - & - & - \\
\hline \multirow{5}{*}{ Multiflora rose } & Distance & - & $*$ & - & $*$ \\
\hline & Distance contrast & - & Quadratic & - & Linear \\
\hline & Distance $*$ total buffer width & - & $*$ & - & - \\
\hline & Distance $*$ basal density & - & - & - & - \\
\hline & Distance $*$ canopy coverage & - & $*$ & - & $*$ \\
\hline \multirow{7}{*}{ Bittersweet } & Between sample effect & - & - & $*$ & - \\
\hline & Distance & $*$ & $*$ & - & - \\
\hline & Distance contrast & Linear & Cubic & - & - \\
\hline & Distance $*$ total buffer width & - & $*$ & - & - \\
\hline & Distance $*$ basal density & - & - & - & - \\
\hline & Distance $*$ canopy coverage & $*$ & $*$ & - & - \\
\hline & Between sample effect & - & - & - & - \\
\hline
\end{tabular}

These trends indicate that multiflora rose was relatively consistent in all forested buffers despite their distance from edge.

Oriental bittersweet showed the most consistent response to increasing distance from the buffer edge. At $10 \mathrm{~m}$, distance and distance/canopy coverage interaction both produced significant reductions in oriental bittersweet $\left(F_{1,17}=3.77\right.$, $P=0.07$ and $F_{1,17}=4.08, P=0.06$, respectively, Table 1$)$ following a linear trend $\left(F_{1,17}=3.77, P=0.07\right.$, Figure 5$)$. At $20 \mathrm{~m}$, distance, distance/total buffer width interaction and distance/canopy coverage interaction showed main effects on the reduction of oriental bittersweet $\left(F_{1.86,18.64}=2.80, P=\right.$ $0.09 ; F_{20.50,18.64}=1.90, P=0.09$; and $F_{1.86,18.64}=3.17, P=$ 0.07 , respectively, Table 1$)$ following a cubic trend $\left(F_{1,10}=\right.$ 4.50, $P=0.06$, Figure 5). No main effects were observed at $35 \mathrm{~m}$ or $55 \mathrm{~m}$ to affect oriental bittersweet prevalence; however, bittersweet levels continued to drop to low mean levels $(\sim 1-2 \%)$ at the furthest distances away from the edge.

\section{Discussion}

By definition, corridors exist in highly fragmented landscapes. Riparian corridors are especially prone to edge effects because the stream bank itself creates another source for repeated disturbance. Furthermore, as many riparian corridors exist as "buffer" strips intended to prevent sediment and nutrient runoff $[8,19]$, corridor soils are often nutrient rich. Increased resource availability and disturbance regimes contribute to enhanced invasive plant dominance [25]. The combination of frequent disturbance and increased resource availability makes it unsurprising that invasive plant occurrence is frequent in the riparian corridors of the White Clay Creek watershed. Although we set our alpha level at 0.10 to compensate for lower sample size, which increased the threshold for rejecting the null hypothesis as compared to other studies, we feel our results indicated observable trends that will aid future management decisions for corridor management. In particular, although multiflora rose and 


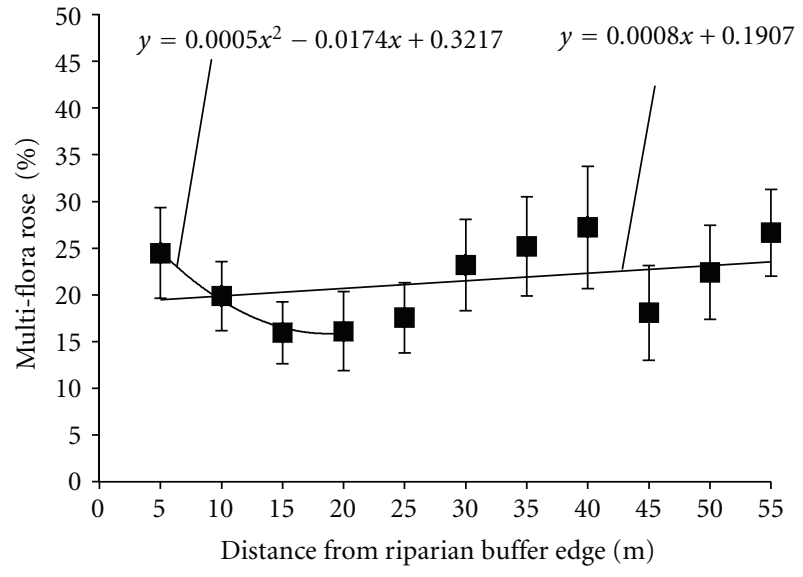

Figure 4: The prevalence of multiflora rose away from the edge of forested riparian buffers in Delaware and Pennsylvania, 20072008. Within-subject contrasts indicated a significant $(P<0.10)$ decreasing quadratic trend through $20 \mathrm{~m}$ but a linear increasing trend through $55 \mathrm{~m}$.

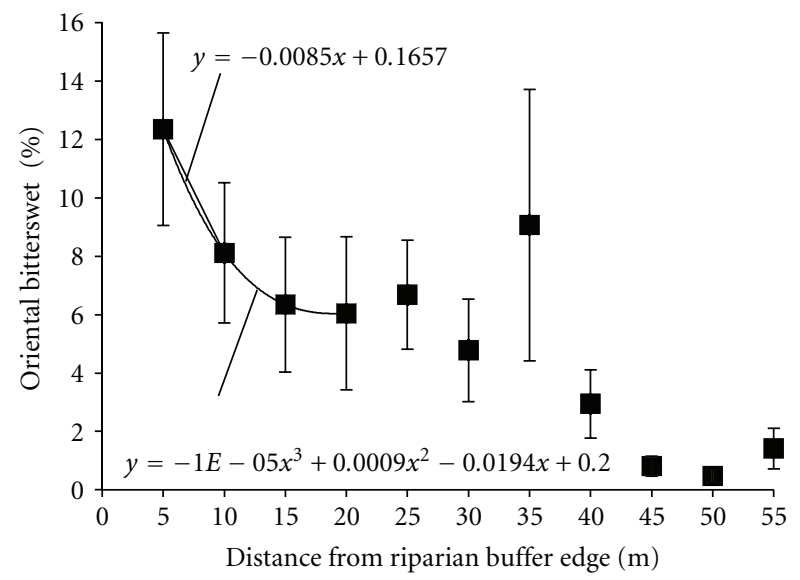

FIGURE 5: The prevalence of multiflora rose away from the edge of forested riparian buffers in Delaware and Pennsylvania, 20072008. Within-subject contrasts indicated a significant $(P<0.10)$ decreasing linear trend through $10 \mathrm{~m}$ and a decreasing cubic trend through $20 \mathrm{~m}$.

Japanese honeysuckle showed little change in prevalence across different buffer widths, notable reductions occurred in oriental bittersweet occurred by $15 \mathrm{~m}$ and garlic mustard by $25 \mathrm{~m}$. We will discuss possible reasons for these relationships in all four species.

Multiflora rose was the most commonly occurring invasive plant and showed no decline across corridor widths. Its frequency should not be surprising given the extent to which it was historically planted across the landscape. Multiflora rose was introduced from Japan and Korea in the 1860s and promoted across the eastern half of the United States as "living fences" and for enhancement of wildlife habitat [26]. Two of the owners of farms in the study area relayed memories of planting multiflora roses supplied by the government during WWII when wire fences were removed for metal drives. Its long history in the study area may partially account for its establishment throughout the widths of most corridors. Also, there are multiple varieties of multiflora rose [27], leading to the possibility there could be some cultivars that are better suited to interior forest conditions and others that are more competitive at corridor edges. Although we did not note cultivars in this study, we encourage future researchers to study this possibility. Further, multiflora rose seeds are dispersed through bird scat [26], which may skew propagule pressure into corridors by disproportionately vectoring seeds into forested areas where birds roost and nest. Our study area also has a high population of white-tailed deer [23] and multiflora rose, garlic mustard, and Japanese honeysuckle has been shown to be less susceptible to deer herbivory than many native species and some other nonnative species $[28,29]$. Preferred browsing on native plants by deer is one example of how enemy release can enhance the competitive abilities of nonnative plants in novel habitats.

In addition to being resistant to deer herbivory and having multiple varieties like multiflora rose [30], Japanese honeysuckle has also been shown to be shade-tolerant, and it benefits from an extended growing season as an evergreen [26]. A vining, climbing habit allows Japanese honeysuckle to make use of space even after another plant has become established. The combination of its growth pattern, shade tolerance, extended growing season, and deer resistance may explain the lack of response to corridor width.

While oriental bittersweet shares Japanese honeysuckle's vining habit and its seeds can germinate in partial to full shade [31], it is considered shade intolerant [32]. Bittersweet also does not share the resistance to deer herbivory displayed by other nonnative species, with at least one study showing a reduction in oriental bittersweet in response to deer browsing [28]. Therefore, the declines in oriental bittersweet as a function of buffer width and canopy coverage interactions were not surprising.

Unlike oriental bittersweet, garlic mustard is highly resistant to deer herbivory and has been shown to respond positively to deer browsing on its competitors [29]. While described as shade-tolerant [33], garlic mustard has also been shown to positively respond to increased light availability [34]. While its shade tolerance and deer herbivory may allow garlic mustard to exist in forest interiors, it has previously been shown to be more competitive in forest edges than in forest interiors [35]. Our results suggest that modest increases in corridor width along with canopy coverage interactions have the potential to limit garlic mustard recruitment.

Reactions to distance from buffer edge and canopy coverage in garlic mustard and oriental bittersweet support the assertion that because these species are less prevalent in forest interiors, expanding forested areas will decrease their competitive advantage over native species in riparian corridors. However, the disappearance of these significant trends after $20 \mathrm{~m}$ is troubling. It is possible that our sample sizes for larger corridor widths were simply too small to detect a decline in prevalence beyond $20 \mathrm{~m}-\mathrm{a}$ consequence of the relative rarity of corridors beyond this width. It is also possible that the higher rates of disturbance within riparian buffers diminishes the interior forest character of these corridors 
such that they no longer cause a decline in invasive species within their interiors. We recommend further research to investigate why small populations of nonnative species can still exist at far distances from corridor or forest edges.

The extent to which expanding riparian corridors has the desired effect of restricting invasive plants and promoting native biodiversity will vary according to the invasive plants present in the area and the response of that particular ecosystem's ecologically important plants to forest interior conditions. The fact that we observed a lack of corridorinduced declines in Japanese honeysuckle and multiflora rose illustrates this point, and we encourage further research to clarify these results. However, because data still show that oriental bittersweet and garlic mustard showed a decline and leveling off by $15-25 \mathrm{~m}$, this indicates that increasing buffer width will be more effective at excluding some invasive plants than others and that some native plants will likely respond better than others to similar conditions. This suggests that increasing corridor width may not only improve wildlife habitat by creating more of it, but by enhancing its quality by restraining the influx of some invasive vegetation and promoting plants native to the ecosystem in question and their associated herbivores. We further encourage future research to determine if a reduction in the nonnative plant assemblage, as compared to its complete elimination, will still improve trophic responses and ecosystem function.

\section{References}

[1] L. Fahrig, "Effects of habitat fragmentation on biodiversity," Annual Review of Ecology, Evolution, and Systematics, vol. 34, pp. 487-515, 2003.

[2] L. Fahrig, "Effect of habitat fragmentation on the extinction threshold: a synthesis," Ecological Applications, vol. 12, no. 2, pp. 346-353, 2002.

[3] P. Bierzychudek, "The demography of jack-in-the-pulpit, a forest perennial that changes sex," Ecological Monographs, vol. 52, no. 4, pp. 335-351, 1982.

[4] G. R. Matlack, "Plant species migration in a mixed-history forest landscape in eastern North America," Ecology, vol. 75, no. 5, pp. 1491-1502, 1994.

[5] O. Honnay, H. Jacquemyn, B. Bossuyt, and M. Hermy, "Forest fragmentation effects on patch occupancy and population viability of herbaceous plant species," New Phytologist, vol. 166, no. 3, pp. 723-736, 2005.

[6] K. MacQuarrie and C. Lacroix, "The upland hardwood component of Prince Edward Island's remnant Acadian forest: determination of depth of edge and patterns of exotic plant invasion," Canadian Journal of Botany, vol. 81, no. 11, pp. 11131128, 2003.

[7] J. E. Kundell and T. C. Rasmussen, "Recommendations of the 1995 Georgia Board of Regents'scientific panel on evaluating the erosion measurement standard defined by the Georgia Erosion and Sedimentation Act," in Proceedings of the Georgia Water Resources Conference, pp. 211-217, 1995.

[8] S. Wenger, A Review of the Scientific Literature on Riparian Buffer Width, Extent, and Vegetation, University of Georgia, Institute of Ecology, Office of Public Service and Outreach, Athens, Ga, USA, 1999.

[9] M. A. Rickey and R. C. Anderson, "Effects of nitrogen addition on the invasive grass Phragmites australis and a native com- petitor Spartina pectinata," Journal of Applied Ecology, vol. 41, no. 5, pp. 888-896, 2004.

[10] J. H. Lawton and K. C. Brown, "The population and community ecology of invading biological sciences," Philosophical Transactions of the Royal Society of London B, vol. 314, no. 1167, pp. 607-617, 1986.

[11] J. M. Crawley, “The population biology of invaders," Philosophical Transactions of the Royal Society of London B, vol. 314, no. 1167, Article ID 10.1098/rstb.1986.0082, pp. 711-731, 1987.

[12] D. W. Tallamy, "Do alien plants reduce insect biomass?" Conservation Biology, vol. 18, no. 6, pp. 1689-1692, 2004.

[13] M. J. Samways, P. M. Caldwell, and R. Osborn, "Groundliving invertebrate assemblages in native, planted and invasive vegetation in South Africa," Agriculture, Ecosystems and Environment, vol. 59, no. 1-2, pp. 19-32, 1996.

[14] M. G. Cripps, M. Schwarzländer, J. L. McKenney, H. L. Hinz, and W. J. Price, "Biogeographical comparison of the arthropod herbivore communities associated with Lepidium draba in its native, expanded and introduced ranges," Journal of Biogeography, vol. 33, no. 12, pp. 2107-2119, 2006.

[15] Y. T. Wu, C. H. Wang, X. D. Zhang et al., "Effects of saltmarsh invasion by Spartina alterniflora on arthropod community structure and diets," Biological Invasions, vol. 11, no. 3, pp. 635-649, 2009.

[16] A. Yoshioka, T. Kadoya, S. I. Suda, and I. Washitani, "Impacts of weeping lovegrass (Eragrostis curvula) invasion on native grasshoppers: responses of habitat generalist and specialist species," Biological Invasions, vol. 12, no. 3, pp. 531-539, 2010.

[17] E. Gerber, C. Krebs, C. Murrell, M. Moretti, R. Rocklin, and U. Schaffner, "Exotic invasive knotweeds (Fallopia spp.) negatively affect native plant and invertebrate assemblages in European riparian habitats," Biological Conservation, vol. 141, no. 3, pp. 646-654, 2008.

[18] R. T. Paine, "Food webs: linkage, interaction strength and community infrastructure," Journal of Animal Ecology, vol. 49, no. 3, pp. 666-685, 1980.

[19] R. T. Mander, V. Kuusemets, K. Lohmus, and T. Mauring, "Efficiency and dimensioning of riparian buffer zones in agricultural catchments," Ecological Engineering, vol. 8, no. 4, pp. 299-324, 1997.

[20] C. R. Blinn and M. A. Kilgore, "Riparian management practices: a summary of state guidelines," Journal of Forestry, vol. 99, no. 8, pp. 11-17, 2001.

[21] O. Honnay, K. Verheyen, and M. Hermy, "Permeability of ancient forest edges for weedy plant species invasion," Forest Ecology and Management, vol. 161, no. 1-3, pp. 109-122, 2002.

[22] E. D. Yates, D. F. Levia Jr, and C. L. Williams, "Recruitment of three non-native invasive plants into a fragmented forest in southern Illinois," Forest Ecology and Management, vol. 190, no. 2-3, pp. 119-130, 2004.

[23] M. Corrozi, A. Homsey, G. Kauffman, E. Farris, and M. Seymour, "White Clay Creek state of the watershed report," Tech. Rep., Institute for Public Administration-Water Resources Agency University of Delaware, Newark, NJ, USA, 2008.

[24] R. H. Canfield, "Application of the line interception method in sampling range vegetation," Journal of Forestry, vol. 39, no. 4, pp. 388-394, 1941.

[25] K. Stinson, S. Kaufman, L. Durbin, and F. Lowenstein, "Impacts of garlic mustard invasion on a forest understory community," Northeastern Naturalist, vol. 14, no. 1, pp. 73-88, 2007.

[26] J. Miller, "Exotic invasive plants in southeastern forests," in Proceedings of the USDA Forest Service and Tennessee Exotic 
Plants Council, K. Britton, Ed., Exotic Pests of Eastern Forests, USDA, Nashville, Tenn, USA, 1997.

[27] C. Paris and T. Maney, "Rosa multiflora and its progeny," Proceedings of the Iowa Academy of Sciences, vol. 46, pp. 149160, 1939.

[28] C. R. Rossell, S. Patch, and S. Salmons, "Effects of deer browsing on native and non-native vegetation in a mixed oak-beech forest on the atlantic coastal plain," Northeastern Naturalist, vol. 14, no. 1, pp. 61-72, 2007.

[29] T. M. Knight, J. L. Dunn, L. A. Smith, J. Davis, and S. Kalisz, "Deer facilitate invasive plant success in a pennsylvania forest understory," Natural Areas Journal, vol. 29, no. 2, pp. 110-116, 2009.

[30] C. D. Huebner, "Vulnerability of oak-dominated forests in West Virginia to invasive exotic plants: temporal and spatial patterns of nine exotic species using Herbarium records and land classification data," Castanea, vol. 68, no. 1, pp. 1-14, 2003.

[31] D. T. Patterson, The ecology of oriental bittersweet, Celastrus orbiculatus, a weedy introduced Ornamental vine, Ph.D. thesis, Duke University, Durham, NC, USA, 1974.

[32] J. Miller, "Nonnative invasive plants of Southern forests: a field guide for identification and control," USDA Forest Service General Technical Report SRS-62, 2003.

[33] J. P. Grime, J. G. Hodgson, and R. Hunt, Comparative Plant Ecology, Unwin Hyman, Boston, Mass, USA, 1988.

[34] J. F. Meekins and B. C. McCarthy, "Responses of the biennial forest herb Alliaria petiolata to variation in population density, nutrient addition and light availability," Journal of Ecology, vol. 88, no. 3, pp. 447-463, 2000.

[35] J. F. Meekins and B. C. McCarthy, "Effect of environmental variation on the invasive success of a nonindigenous forest herb," Ecological Applications, vol. 11, no. 5, pp. 1336-1348, 2001. 

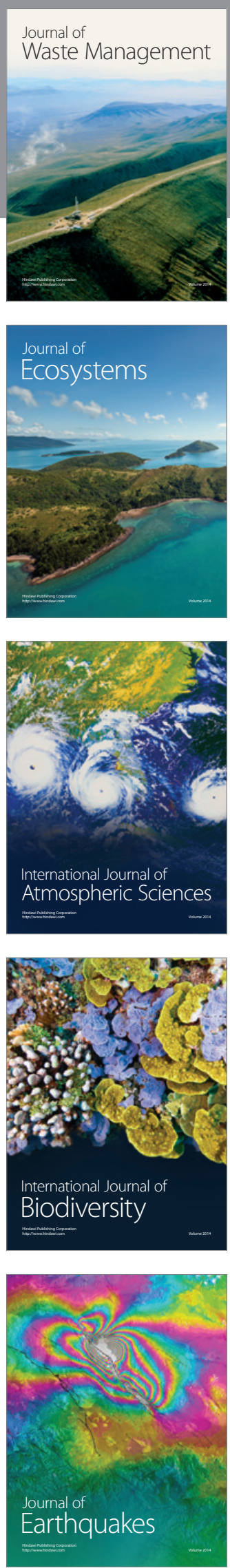


Submit your manuscripts at

http://www.hindawi.com
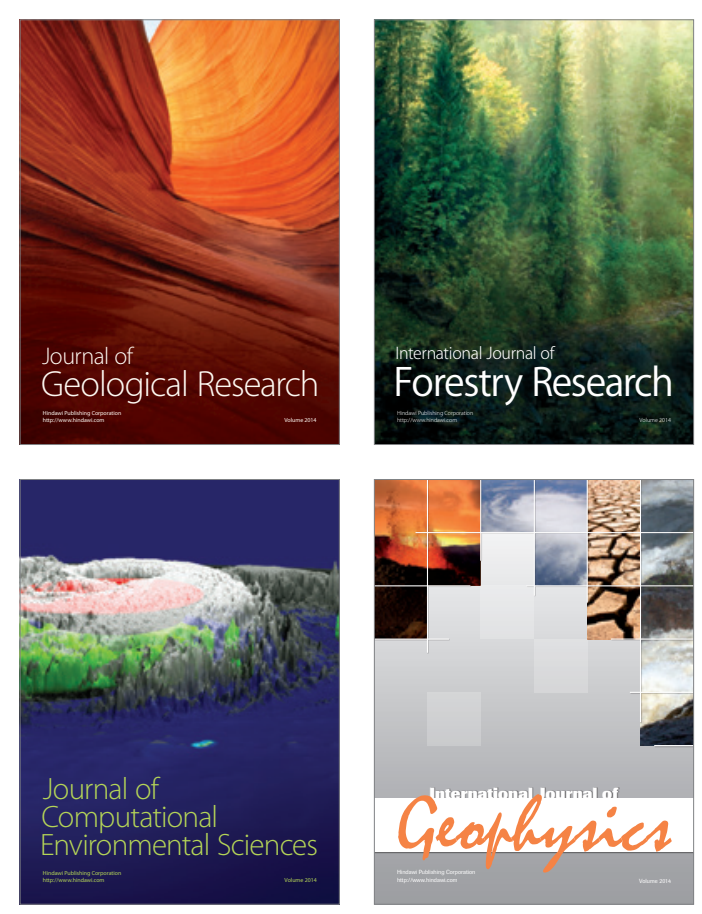
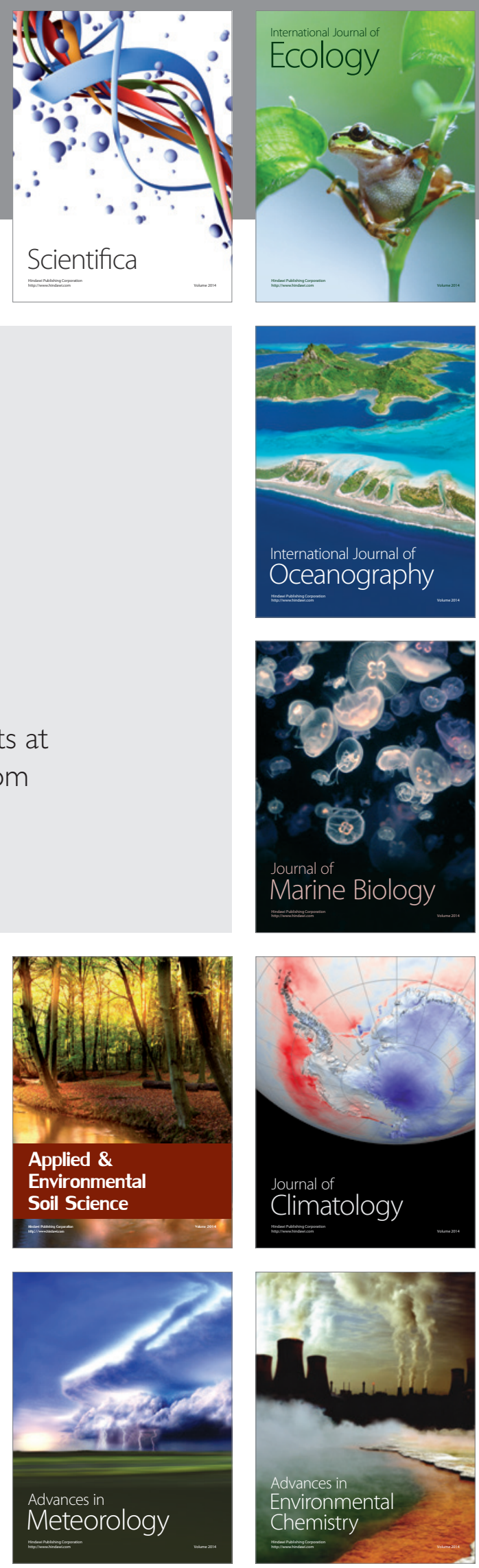